УДК 159.99

\title{
СТРАХ НА ВОЙНЕ: ДЕСТРУКТИВНЫЙ ФАКТОР ИЛИ ПСИХОЛОГИЧЕСКИЙ РЕСУРС?
}

\author{
Караяни Александр Григорьевич \\ Караяни Юлия Михайловна
}

В статье рассматриваются особенности переживания страха участниками боевых действий. Соответственно, анализируются симптомы, факторы, катализаторы и функции страха. Рассматривается влияние страха на поведение участников боевых действий, раскрываются феномены психологического заражения и поражения. Описывается природа страха и особенности его проявлений во время боевых действий. Приводятся результаты исследований военных теоретиков и психологов относительно дезорганизующей роли страха. Однако автором страх рассматривается как естественная, необходимая и полезная реакция воина на опасность. Вместе с тем представлена динамика переживания и психологические последствия страха, раскрывается его влияние на боевую деятельность воинов. Приводятся конкретные примеры и реальные случаи, иллюстрирующие морально-психологические возможности воинов, переживающих страх. Описывается активизирующая роль страха, его конструктивные функции. Анализируются отдельные аспекты психологического состояния участников боя и мобилизующие свойства страха. В данном контексте страх выступает как одна из самых "энергоемких» эмоций человека. Обосновываются направления по использованию страха как ресурса боевой активности воинов. Описываются особенности регуляции страха, актуализируется необходимость развития социальных мотивов (любовь к Родине; вера в Бога, справедливость, победу; ненависть к врагу; чувство долга и т. д.) у воинов. Анализируются психологические механизмы регуляции страха. В заключении обозначаются перспективные направления развития военной психологии и актуальность создания практико-ориентированных методов и методик, нацеленных на оказание воздействий, направленных на мобилизачию психологических ресурсов участников боевых действий, управления страхом, оптимизацию их морально-психологического состояния и активизацию деятельности. 
Ключевые слова: страх, факторы страха, функции страха, бой, война, методы овладения страхом, возможности, ресурсы, управление.

Страх - одна из самых таинственных и противоречивых эмоций. Сформировавшийся в процессе эволюции как сигнально-предупредительная реакция человека на опасность, страх нередко дезинформирует человека о масштабах внешней угрозы. Он, одновременно, и верный «сторожевой пес», бдительно стерегущий жизнь и здоровье человека, и один из самых жестоких «палачей», изощренный в пытках человеческой души и плоти. Страх является мощным катализатором физических, духовных сил и энергии человека и, в то же время, он способен парализовать его способность противостоять опасности.

Каждый из нас сталкивается со страхом практически с самого рождения, а затем многократно встречается с ним на протяжении жизни. Влияние страха на человеческое поведение чрезвычайно многообразно. От простейших вегетативных реакций и незначительного замедления действий до тотального паралича организма. Страх захватывает человеческую плоть, его нервно-психическую и духовную организацию.

Реестр человеческих страхов достаточно велик. Иногда он проявляется в едва уловимом, смутном страхе-беспокойстве, а порой в виде животного ужаса, ощущения наступления чуть ли не вселенской катастрофы. Действительно, страх многолик, вездесущ, заразителен. Существуют специфические формы страхов, находящихся на границах нормы и патологии человеческой психики. Можно так же говорить о страхах матери, влюбленного, горожанина, студента и т. д. Однако, пожалуй, наиболее «благодатная» почва для проявления страха во всех его ипостасях создается на войне, в боевой обстановке.

Известный военный теоретик и эмпирический психолог Карл фон Клаузевиц, характеризуя войну, подчеркивал, что главной ее стихией является опасность [7]. Реакция на опасность, страх, - неизбежный атрибут войны, оказывающий влияние на все стороны боевой деятельности военнослужащих. Одним из последствий такого влияния является существенное снижение боевой эффективности бойцов, прежде всего - точности огневого поражения противника. Изучение показывает, что из-за страха эффективность огня в бою просто ничтожна. В Первую мировую войну на поражение одного солдата противника расходовалось 2,5-5 тыс. патронов, во Вторую мировую войну - 10 тыс., в локальных военных конфликтах XX в. - 50 тыс. [4, с. 43], во время войны во Вьетнаме на каждую пораженную американскими солдатами цель приходилось 200 000-400 000 патронов [9]. 
Более драматичным последствием страха является психотравматизация участников боевых действий. О масштабах этого грозного явления можно судить по отношению числа психологических потерь к количеству раненых. Наиболее полная статистика такого соотношения имеется в армии США, где в годы Первой мировой войны соотношение было примерно 10 к 100, во Второй мировой войне - 36 к 100. По данным Р. Габриэля, во время Второй мировой войны американские войска потеряли 504 тыс. человек в результате психических расстройств на поле боя. Такого количества личного состава вполне достаточно для формирования 50 боевых дивизий. В арабо-израильской войне 1973 г. почти одна треть потерь израильтян была вызвана психологическими причинами. Примерно то же самое наблюдалось в египетских войсках. При вторжении израильтян в Ливан в 1982 г. количество потерь от психических расстройств уже в два раза превысило количество убитых и составило 27 \% от общего количества раненых [3]. Во время войны во Вьетнаме психогенные потери составили уже $30 \%$ от числа участников боевых действий. В ходе боевых действий в Ираке и Афганистане - 12-20\%.

Страх и его психологические последствия обладают огромной силой заражения. По данным Дж. Долларда, опросившего сотни ветеранов Второй мировой войны, 75 \% из них были уверены в том, что «страх может быть инфекционным, передаваться от одного солдата к другому». В исследовании Штуффера 83 \% опрошенных утверждали, что у них был опыт наблюдения, как человеческие нервы «ломаются» на фронте. 70 \% из 1700 американских ветеранов, обследованных в Италии в 1944 г., показали, что их психика давала сбои при виде последствий психотравматизации другого человека [18]. История войн и военного искусства знает немало случаев, когда страх одиночных солдат обретал силу эпидемии и превращался в неудержимую панику многотысячной толпы.

Результаты ряда исследований показывают, что страх является не только следствием, но и важнейшей целью и одним из самых разрушительных средств вооруженного противоборства. Еще в начале XX в. русский боевой офицер и эмпирический психолог В. Н. Полянский (см. табл. 1) на основе анализа сражений предшествующих веков установил, что победа и поражение в бою в решающей степени определяются причинами психологического порядка. Достаточно, по его мнению, в среднем вывести из строя физически 17-20 \% личного состава противника, чтобы заставить живых бойцов отказаться от продолжения боевых действий. Остальные 80 \% терпят чисто психологическое поражение. Из этого В. Н. Полянский сделал вывод о том, цель боя - «не обязательно убить, но обязательно устрашить» $[13$, с. 53-54]. 


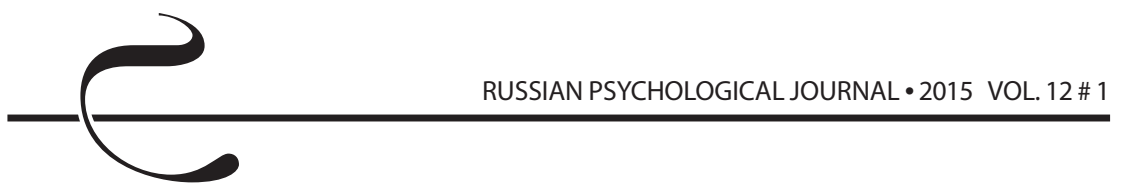

Таблица 1.

Страх как фактор достижения победы над противником

\begin{tabular}{|l|c|c|}
\hline \multirow{2}{*}{\multicolumn{1}{|c|}{ Войны }} & \multicolumn{2}{|c|}{ Факторы достижения победы } \\
\cline { 2 - 3 } & $\begin{array}{c}\text { Физическое уничто- } \\
\text { жение противника }\end{array}$ & $\begin{array}{c}\text { Психологическое } \\
\text { подавление (устрашение) } \\
\text { противника }\end{array}$ \\
\hline $\begin{array}{l}\text { Войны 18-19 вв. } \\
\text { (В. Н. Полянский) }\end{array}$ & $20 \%$ & $80 \%$ \\
\hline Крупнейшие сражения XX в. & $6 \%$ & $94 \%$ \\
\hline
\end{tabular}

Из таблицы 1 видно, что в XX в. порог «моральной упругости», т. е. способности продолжать сражаться, несмотря на боевые потери, снизился более чем в 2 раза. По результатам исследований группы американских специалистов 80 крупнейших боевых событий XX в. установлено, что сегодня войска, в среднем, терпят психологическое поражение уже при физических потерях, равных 6 \% личного состава. Неслучайно отечественная военнопсихологическая наука с первых шагов своего самостоятельного развития была убеждена в том, что «подготовить бой, подготовить наступление равносильно понятию - подорвать, расшатать, убить психические силы противника» $[8$, с. 163, 246].

На протяжении длительного времени страх трактовался военными теоретиками и практиками как однозначно негативная эмоция. Исходя из такой позиции, предлагалось «бороться» со страхом, «побеждать» страх, «преодолевать и пресекать» его. Как показывает приведенная выше статистика, такая позиция оказалась необоснованной, а предпринимавшиеся на ее основе попытки победить страх оказались несостоятельными.

Задача современной военной психологии видится не в том, чтобы «пригвоздить» страх к столбу позора, а в том, чтобы предложить бойцу реальные способы и средства, позволяющие эффективно действовать в опасной обстановке, превратить страх из «пут» и «оков» участника боевых действий в его боевой психологический ресурс.

Для этого, прежде всего, необходимо познать страх (выявить его природу, факторы, катализаторы, виды, функции, симптомы и динамику проявления в боевой обстановке), принять его (признать его в качестве атрибута экстремальной деятельности) и рационально использовать порождаемую им энергию.

Изучение природы страха позволяет утверждать, что страх в бою - это не удел трусов, а «нормальная, неизбежная, полезная реакция на опасность, как сигнал опасности, производящийся человеческим организмом при обнаружении признаков опасности в окружающем мире» [18]. О «нормальности» 
страха свидетельствует его фактическая всеобщность. Сегодня уже хорошо известно, что среди психически и соматически нормальных людей нет абсолютно бесстрашных. Один из активных участников героической обороны Москвы осенью 1941 г. Б. Момыш-Улы подчеркивал: «за сто с лишним боев я еще ни одного бесстрашного человека не встречал. Никто, сознавая опасность смерти, не идет в бой без страха, а если иногда и идет, значит, не сознает опасности, но это не есть бесстрашие. Страх испытывает каждый и множество раз в жизни... бесстрашие как таковое вообще в природе не существует. Бесстрашных людей нет на свете» [12, с. 18].

Исследования, проведенные в годы Второй мировой войны группой американских психологов под руководством Э. Боринга показали, что $90 \%$ опрошенных участников боевых действий испытывает выраженный страх (10\% опрошенных затруднились оценить свое отношение. Есть немало свидетельств того, что среди них подавляющее большинство составляют те, кто стесняются признаться в переживании страха). Было установлено, что страх в бою захватывает воинов «целиком», отражаясь в соматической, физиологической, психологической сферах. Более 50 \% воинов, переживающих страх, испытывают слабость, тошноту, каждый десятый - неконтролируемое мочеиспускание или диарею [2].

Аналогичные данные были получены в 1944 г. психологической службой ВВС США. П. Мокор, анализируя полученную в исследовании статистику, отмечает, что из 4500 опрошенных летчиков, штурманов, стрелков-радистов, участвовавших в боевых действиях в Англии, на Средиземном море, на Тихом океане $99 \%$ заявили, что во время боевых действий испытывали страх. Более 33 \% опрошенных офицеров и 42 \% солдат переживали страх во время каждого вылета, а порядка 62 \% офицеров и 71 \% солдат - в половине вылетов [11, с. 58-59].

На многих участников боевых действий страх оказывает дезорганизующее и нередко парализующее влияние. В годы Второй мировой войны в течение нескольких лет группой специалистов под руководством С. Л. А. Маршалла на предмет изучения страха обследовались тысячи американских солдат и офицеров из четырехсот пехотных рот. Методами опроса, перекрестной проверки, очной ставки, свидетельских показаний выявлялась степень участия военнослужащих в бою. Результаты этого исследования показали, что «из бойцов, которые в каждый момент боевых действий могут и должны пускать в ход вверенное им оружие, всего 15 \% ведут огонь по неприятельским позициям. Если к этой ничтожной части непосредственно действующих бойцов присоединить тех, кто проявляет какую-либо личную инициативу..., то процент реальных участников боя может быть доведен до 25 \%» [10, с. 50]. То есть полезное участие в бою принимает лишь один боец из четырех. 
Признание естественности страха позволяет элиминировать один из самых распространенных на войне страхов - страх струсить на поле боя и подвести своих боевых товарищей, т. е. «страх перед страхом».

Важнейшим моментом познания страха является выяснение его функций. Собственно широкая распространенность страха в боевой обстановке связана с тем, что «в идеале» он выполняет чрезвычайно полезные функции. Во многом именно благодаря страху человек способен превратиться в настоящего воина. В таблице 2 отражены важнейшие функции страха, обеспечивающие это превращение [6]. В частности, видно, что страх в максимальной степени мобилизует все организмические ресурсы, физическую, нервную и психическую энергии человека. Он делает человека менее уязвимым для боли, ранения, неблагоприятных обстоятельств боя. Мотивация выживания в обстановке страха смерти и боли является мощнейшим двигателем активности. Страх это «ядерный» реактор в душе человека, одно из самых ресурсных и высокоэнергетических состояний воина. Некоторые специалисты сравнивают его с высокооктановым топливом, способным мгновенно «разгонять» организм и психику человека до огромных «скоростей» функционирования.

Таблица 2.

\section{Функции страха в бою}

\begin{tabular}{|c|c|c|}
\hline $\begin{array}{l}\text { № } \\
\Pi / \Pi\end{array}$ & Феномены страха & Функции \\
\hline 1. & $\begin{array}{l}\text { Тревога, выделение в кровь адренали- } \\
\text { на и норадреналина }\end{array}$ & $\begin{array}{l}\text { Приведение в состояние бдительно- } \\
\text { сти, боевой настороженности }\end{array}$ \\
\hline 2. & $\begin{array}{l}\text { Повышение частоты сердцебиений, } \\
\text { перераспределение кровотока (от вну- } \\
\text { тренних органов к скелетным мышцам) }\end{array}$ & $\begin{array}{l}\text { Лучшее снабжение мышц энергией } \\
\text { для осуществления адаптивной реак- } \\
\text { ции «бей или беги» }\end{array}$ \\
\hline 3. & $\begin{array}{l}\text { Увеличение объема легких и } \\
\text { уровня дыхания }\end{array}$ & $\begin{array}{l}\text { Увеличение объема кислорода, по- } \\
\text { ступающего в кровь для питания } \\
\text { мышц энергией }\end{array}$ \\
\hline 4. & Увеличение сахара в крови & $\begin{array}{l}\text { Получение «топлива» для быстрой } \\
\text { энергии, необходимой для «аварий- } \\
\text { ной» активности }\end{array}$ \\
\hline 5. & $\begin{array}{l}\text { Отток крови от внутренних органов, } \\
\text { кожи, «перчаточно-носочной» зоны } \\
\text { Сгущение крови }\end{array}$ & $\begin{array}{l}\text { Предупреждение больших кровопо- } \\
\text { терь в случае ранения или травмы }\end{array}$ \\
\hline 6. & Выделение в кровь опиатов & $\begin{array}{l}\text { Обеспечение тотального обезболива- } \\
\text { ния организма в случае ранения или } \\
\text { травмы }\end{array}$ \\
\hline 7. & $\begin{array}{l}\text { Усиленное потоотделение, появление } \\
\text { эффекта «гусиной кожи» }\end{array}$ & $\begin{array}{l}\text { Сохранение температурного баланса } \\
\text { в организме }\end{array}$ \\
\hline 8. & Повышение температуры тела & $\begin{array}{l}\text { Подавление патогенных процессов } \\
\text { в организме в случае ранения, трав- } \\
\text { мы, заболевания }\end{array}$ \\
\hline
\end{tabular}


«Пробуксовка» или срыв любой из перечисленных выше функций страха чреваты снижением или утратой боевых возможностей воина. В этом случае воин лишается той или иной «страховки» и оказывается «незастрахованным» от тех или иных угроз. Если воин не осваивает энергию страха, то страх становится дезорганизующим, парализующим, болезненным и разрушительным психическим состоянием.

Чтобы устранить возникшее противоречие между высокоадаптивными, энергетическими, мобилизующими свойствами страха и его деморализующим и дезорганизующим эффектом, специалисты выделили «контролируемый» и «неконтролируемый» виды страха. Контролируемый страх обладает силой побуждать человека к полезным действиям. Неконтролируемый страх является разрушительным. Когда страх слишком слаб, люди становятся беззаботными и подвергают себя и других к необоснованному риску и опасности. Когда он превышает определенные пороги, обретает силу побуждать человека к бессмысленной панике, которая подвергает опасности его жизнь и жизнь боевых товарищей [18].

Для того чтобы овладеть страхом, необходимо познать его главные факторы. В литературе можно встретить десятки боевых обстоятельств, трактуемых авторами как факторы страха. На воина в бою воздействует огромное количество различных стимулов, среди которых: вспышки взрывов и выстрелов, «фонтанчики» от пуль, пролеты самолетов (вертолетов), перемещение боевой техники, движение противника, перемещение сослуживцев, горящие техника и строения, ранение и гибель сослуживцев, спасительные укрытия, звуки выстрелов и взрывов, крики раненых, команды командиров, крики сослуживцев, крики (боевые кличи) противника, вибрация земли, свист пуль, шелест снарядов, ракетницы, холод, жара, резь глаз от дыма, запах гари, тепло, вкус крови, дрожь тела, «мурашки» по телу, неприятные телесные ощущения, сухость во рту, всплывающие воспоминания, вид трупов, мысли, жар от пожаров, стук собственного сердца, болевые ощущения, апноэ, ощущение усталости и др. [9].

Безусловно, многие из перечисленных стимулов весьма неблагоприятно сказываются на психическом состоянии участников боя, однако далеко не все из них «страхородны». Сегодня специалисты выделяют в качестве основных три фактора (причины, движущие силы) страха: неизвестность, неожиданность, чувство беспомощности.

Народная мудрость, боевой опыт великих полководцев отразили эти факторы в виде своеобразных формул: «чего не знаю, того боюсь», «предупрежден, значит вооружен», «удивил, значит победил», «деньги потерял ничего не потерял; друга потерял - половину потерял; веру потерял - все потерял». 
В свое время еще И. П. Павлов указывал на то, что не сила стимула, а его новизна вызывает охранительную реакцию. Это обстоятельство хорошо иллюстрируется с помощью информационной теории П. В. Симонова. Автор теории доказывает, что для удовлетворения актуальной в каждый момент времени потребности человек должен совершать вполне определенные действия, поэтому ему нужна информация о предметах и условиях, удовлетворяющих эту потребность. Эти положения П. В. Симонов облек в своеобразную формулу: Э = П (Ис - Ин), где Э - эмоция, ее сила и знак, П - сила и качество актуальной потребности, Ин - информация о средствах, прогностически необходимых для удовлетворения существующей потребности, Ис - информация о средствах, которыми человек располагает в данный момент. Из данной формулы видно, что если Ис равна или больше Ин, то эмоциональная реакция будет положительной или нейтральной. Чем меньше будет Ис по сравнению с Ин, тем сильнее будет выражена негативная эмоция. Эмоции будут сильнее выражены и тогда, когда потребность, удовлетворяемая деятельностью, остра [14].

Действие данной формулы можно проследить на следующем примере. Группе военнослужащих предстоит действовать в тылу противника. Потребность в решении боевой задачи и знании обстоятельств ее выполнения очень высока. Следовательно, военнослужащие должны хорошо знать особенности тактики действий, психологии и уровень боевой выучки противника, конкретные характеристики местности, порядок, силы и средства выполнения задачи. Если эти знания достаточны для эффективной деятельности, негативных эмоций у воинов не возникает. Если же информации недостаточно, то у воинов могут возникать беспокойство, тревога и страх. Кроме индивидуального страха, в условиях нехватки информации могут возникать «слухи-пугала», способствующие порождению групповой паники [5].

Таким образом, страх - это сигнал о недостатке важной информации для выполнения боевой задачи и побуждение воина к ее поиску. Не случайно в ряде исследований отечественных [16] и зарубежных [18] психологов отмечается, что солдаты больше всего боятся врага, которого они не могут видеть. Незримый враг кажется сильнее, наделяется не присущими ему качествами. Этот феномен зафиксирован в знаменитых суворовских афоризмах: «удивить значит победить», «у страха глаза велики». Специалисты указывают на то, что быть удивленным врагом - значит утратить средства контроля над страхом.

В. Франкл предложил несколько иную формулу, позволяющую анализировать природу и характеристики страха. Эта формула отражает характер взаимосвязи негативных переживаний и смысла деятельности: 
O = П - С, где О - отчаяние, П - негативное переживание, С - смысл [15]. Из этой формулы видно, что чем более осмысленна деятельность воина, тем меньше вероятность возникновения у него отчаяния, даже при высоких уровнях переживания страдания, страха и т. д. Эта формула выведена на основе идеи Ф. Ницше: «Тот, кто знает, зачем жить, может вынести почти любое как».

Можно сказать, что по В. Франклу, страх - это сигнал о недостатке смысла деятельности. Именно высокий смысл, который вкладывали наши воины в победу в Великой Отечественной войне, способствовал развитию массового самопожертвования и героизма. Важность наделения смыслом участия воинов в смертельных сражениях была осознана и в других армиях. Так, Дж. Аппель и Г. Вибе полагали, что британские солдаты были в состоянии сохранять боевую устойчивость почти в два раза дольше американских, потому что они, в отличие от американцев, «боролись за выживание» [18].

Кроме перечисленных факторов существуют обстоятельства, усиливающие страх, т. е. своеобразные катализаторы страха. К их числу чаще всего относят: время экспозиции факторов страха, боевую усталость, задолженность сна, чувство изолированности и одиночества воинов.

Исследование, проведенное во время Второй мировой войны Дж. Аппелем и Г. Вибе, показало, что страх становится травматическим в прямой зависимости от срока пребывания воинов в боевой обстановке. Дж. Доллард установил, что «длительное подвергание опасности не укрепляет солдата, а разрушает его ограниченные ресурсы». В ряде других исследований было показано, что у каждого солдата есть свой предел нахождения в опасной ситуации, вне которого их эффективная работа в бою снижается. Даже самый сильный и выносливый человек может сломаться психологически, если его «передержать» в обстановке тотального страха [18].

Средний предел времени, в течение которого американские военнослужащие могли более или менее эффективно справляться со страхом, составлял 200-240 дней. После этого срока солдаты становились настолько осторожными и нервозными, что нередко утрачивали боевую эффективность. В то же время британские военнослужащие, получавшие в годы Второй мировой войны четырехдневный отдых после каждых 12 дней боев, могли совладать со страхом до 400 дней (то есть почти вдвое дольше американских) [18]. Выявление этого обстоятельства позволило психологам доказать командованию армии США необходимость ограничить срок пребывания американских военнослужащих в зоне боевых действий 180 днями. 
Особенно негативное влияние на военнослужащих оказывает страх, вызываемый длительным нахождением в непосредственном боевом соприкосновении с противником. Немецким психологом Э. Динтером была выявлена следующая закономерность. По его наблюдениям, моральнопсихологические возможности бойцов начинают медленно расти после 3-5 дней пребывания в опасной ситуации. Потом, в течение 20-25 дней наблюдается их максимальная боевая эффективность, благодаря относительной адаптации к страху. Однако после 40 суток боевого соприкосновения с противником отмечается обвал психологических возможностей бойцов в связи с быстрым нарастанием страха и усталости. Позже американские специалисты подтвердили полученные Э. Динтером результаты и сделали вывод о том, что предел нахождения воинов в непосредственном боевом соприкосновении с противником составляет 30-35 суток [3]. После этого срока необходим отвод войск во вторые эшелоны или резервы.

Практика показывает, что воины имеют не только разные временные пределы сопротивления страху, но и переживают пики страха на различных этапах боя, т. е. отличаются динамикой переживания страха. Я. Агрель выявил, что порядка 39 \% военнослужащих (из 90 \%, признавшихся, что переживают в бою страх) испытывают максимальный страх до начала боя. Порядка 16 \% воинов переживают максимальный страх после боя. И лишь 36 \% максимально подвержены страху непосредственно в бою [17]. Из этого следует, что, по крайней мере, на 60 \% страх - это результат исключительно воображения и памяти, а не объективно существующей опасности.

Питательной почвой для страха является физическое и психологическое одиночество воина на поле боя (отсутствие возможности взаимодействовать с боевыми товарищами; страх попасть в плен или остаться на поле боя раненым и даже убитым). Именно осознание этого обстоятельства в годы Великой Отечественной войны заставило советских военных руководителей и ученых отказаться от представлений об обороне как системе изолированных друг от друга ячеек и перейти к траншейной обороне. К. К. Рокоссовский лично изучал психологическое состояние бойцов, находящихся в ячейках в ходе оборонительных боев за Смоленск и пришел к однозначному выводу, что «надо немедленно ликвидировать систему ячеек и переходить на траншеи» [1]. Переход к траншейной системе обороны позволил преодолеть чувство изолированности воина в бою, открыть простор для взаимной поддержки и взаимопомощи воинов, для действия психологических механизмов взаимного заражения, подражания, группового контроля, что способствовало повышению их устойчивости к страху. 
Перечисленные выше положения позволяют определить основные направления овладения воинами страхом как психологическим ресурсом.

1. Прежде всего, регуляция уровня страха может осуществляться посредством осмысления - придания ясного смысла участию воинов в боевых действиях, формирования у них широких социальных мотивов (любовь к Родине; вера в Бога, справедливость, победу; ненависть к врагу; чувство долга и т. д.) и мотивов боевого товарищества. Осмысленная деятельность «берет» страха ровно столько, сколько его нужно, чтобы сохранить смысл деятельности.

2. Регуляция страха может достигаться посредством элиминации факторов и катализаторов страха в боевой деятельности воинов. Важнейшей задачей здесь является, как подчеркивал один из основателей отечественной военной психологии Г. Шумков, «... предварительное ознакомление воинов с реальными явлениями в бою - в смысле боевой деятельности и в смысле психических переживаний» [16]. Это, по его мнению, «есть предварительное накопление боевого опыта, а, следовательно, и рациональная работа с вредным влиянием сильных переживаний на психику воинов при чувствах тревоги и страха».

Здесь уместно привести простой пример. Одним из самых сильных переживаний на войне является страх боли от ранения, травмы. В основе этого страха лежит незнание психофизиологической феноменологии ранения. Между тем воины, раненные в ходе боя, указывают на феномен тотального обезболивания организма в процессе переживания боевого стресса. Вот как об этом вспоминает один из ветеранов боевых действий в Чеченской Республике: «Мы атаковали противника, продвигаясь за БМП, как за щитом. Огонь противника был шквальным. Вдруг я споткнулся и упал на землю. Быстро вскочил, двинулся вперед, но опять упал, как подкошенный. Что-то заставило меня посмотреть на ногу. Я увидел, что она перебита. Бандиты научились стрелять рикошетом от земли под днище БМП». В кинофильме «Спасти рядового Райана» показан момент высадки десанта союзников, открывающих второй фронт на побережье Франции в 1944 г. В ходе сражения один из бойцов мечется по полю боя в поисках чего-то. Вдруг он обнаруживает искомый предмет, поднимает его, зажимает подмышкой и бежит вперед. Этим предметом оказывается рука бойца, оторванная взрывом практически по плечо. В памяти ветеранов войн хранится немало историй о том, что нередко воины обнаруживали у себя ранения (иногда неоднократные) лишь после боя.

Рассказы воинам таких историй выполняют практически ту же функцию, что и специальная психологическая технология «Систематическая десенсибилизация». Ее суть состоит в том, чтобы мысленно проходить по 
«лестнице» страхов в безопасной обстановке, в условиях соматической релаксации. Страх и релаксация - антагонисты и не могут существовать одновременно. У воинов формируется привычка думать о ранении без страха боли.

Учитывая ограниченность человеческих возможностей сопротивляться неблагоприятным факторам, необходимо следить за тем, чтобы не передерживать воинов в жизнеопасной обстановке. Практика показывает, что устойчивость военнослужащих к страху значительно увеличивается, если они изначально осведомлены о продолжительности своего участия в боевых действиях и сроках возвращения в пункты постоянной дислокации.

3. Для того чтобы управлять страхом, необходимо уметь своевременно распознавать его основные симптомы (см. таблицу 3) $[6,16]$ и «включать» психологические механизмы эффективного задействования или регуляции страха.

Таблица 3.

Симптомы страха

\begin{tabular}{|c|c|c|}
\hline \multicolumn{3}{|c|}{ СИМПТОМЫ СТРАХА } \\
\hline $\begin{array}{c}\text { Автоматические } \\
\text { реакции }\end{array}$ & $\begin{array}{c}\text { Психологические } \\
\text { реакции }\end{array}$ & Чрезвычайные реакции \\
\hline Дрожь & $\begin{array}{l}\text { Неспособность принимать } \\
\text { решения }\end{array}$ & $\begin{array}{l}\text { Неконтролируемые агрес- } \\
\text { сия и гнев }\end{array}$ \\
\hline $\begin{array}{l}\text { Учащенное сердцебиение } \\
\text { и дыхание }\end{array}$ & $\begin{array}{l}\text { Сосредоточенность на } \\
\text { второстепенных деталях }\end{array}$ & Замирание под огнем \\
\hline Иррациональный смех & Нехватка уверенности & \\
\hline Чрезмерное потение & Расстройство дисциплины & \\
\hline Сухость во рту & $\begin{array}{l}\text { Расстройство взаимоотно- } \\
\text { шений воинов }\end{array}$ & \\
\hline «Шевеление» волос & Отчаяние & \\
\hline Ощущение «гусиной кожи» & & \\
\hline $\begin{array}{l}\text { Побледнение (пожелте- } \\
\text { ние) лица }\end{array}$ & & \\
\hline $\begin{array}{l}\text { Повышение температуры } \\
\text { тела }\end{array}$ & & \\
\hline Туннельное зрение & & \\
\hline Слуховые исключения & & \\
\hline Реакция «бей или беги» & & \\
\hline
\end{tabular}

Чем раньше будут обнаружены симптомы страха, тем больше возможностей довести его до оптимального уровня. Для этого могут быть использованы приемы экстренной психологической саморегуляции, в основе которых 
лежат мышечная релаксация, изменение тонуса дыхания, плацебо-технологии типа «рефлекторного закрепления психических состояний». Накапливаемые в процессе жизни и фиксируемые с помощью специальных якорей проактивные состояния могут мгновенно воспроизводиться в опасной ситуации при активации якоря.

4. Представляется, что определенный потенциал регуляции страха содержится в психологических механизмах метода парадоксальной интенции [14]. «Планирование» моментов возникновения страха на этапах боя, стремление «обнаружить» и «почувствовать» его могут существенно снизить страх. Полученный в этом случае эффект можно обозначить как «Эффект комнаты страха». Когда посетители комнаты страха входят в нее с воображением, воспаленным рассказами тех, кто был в ней раньше, и ожидают, что «вот сейчас выскочит ведьма», а «сейчас появится мертвец» и т. п., страха не возникает. Этот эффект проявляется сильнее тогда, когда ожидания облекаются в юмористическую форму.

Желание страха уничтожает страх подобно тому, как желание боли элиминирует боль. Известно, что на нашей планете значительное количество людей ищут боль и наслаждаются ею. Например, в Индии проживают целые семьи и кланы, в культуру которых входит ритуальное самоистязание. В этом пристрастии есть полезное зерно. Оно доказывает то, что человек может не просто привыкать к крайне неприятным переживаниям, а принимать и даже желать их. Не случайно, в последнее время специалисты сходятся на том, что подобные психологические механизмы могут быть целенаправленно использованы для преодоления страха.

Совсем недавно люди поняли, что не следует сразу же сбивать температуру при инфекционных заболеваниях, т. к. она убивает болезнетворных микробов. Воинам предстоит научиться «не сбивать» страх вплоть до его критических значений.

5. Наиболее перспективным направлением исследования страха и способов его интеграции в боевую деятельность представляется произвольная трансформация страха в проактивные эмоции (гнев, ненависть, злость). Такой переход может осуществляться с помощью «раскачивающих» («нагнетающих», «помповых») технологий использования страха, заключающихся в сознательном и управляемом мощном нагнетании страха и резком выбросе его энергии в конкретное действие в виде гнева.

Почти 70 лет назад участник более 100 сражений и боев Великой Отечественной войны Б. Момыш-улы подчеркивал: «инстинкт самосохранения имеет две стороны. Первая - человек бежит с целью самосохранения, вторая - человек с этой же целью нападает и защищается... Эту вторую сторону в человеке нужно развивать, так как она толкает на защиту, на 


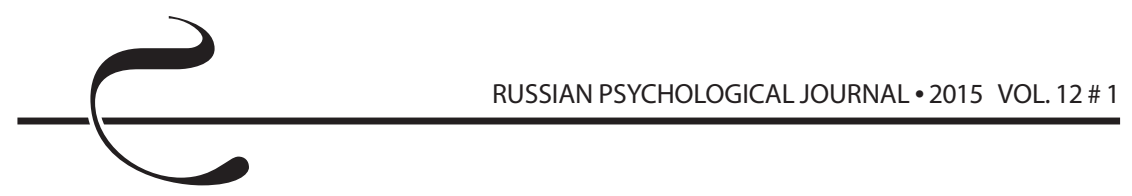

нападение. Самосохранение - это благородная черта не только человека, но и всего живого. Вот почему это чувство является первородным двигателем в бою» $[12$, с. 19].

Таким образом, страх - естественная и полезная реакция воина на опасность, неизвестность и внезапность боевой обстановки. Страх - одна из самых «энергоемких» эмоций человека. Выполнив свою главную, сигнальную функцию, он становится дисфункциональным и дезорганизующим деятельность. Задача состоит не в том, чтобы «уничтожить» страх, а в том, чтобы подчинить его своей власти и превратить в ресурс боевой деятельности.

Более ста лет назад, осмысляя уроки русско-японской войны (1904-1905 гг.), Г. Шумков подчеркивал, что военная психология лишь тогда станет наукой, полезной командиру, когда она укажет пути повышения боевых возможностей своих войск и понижения боевых сил противника. Страх, как представляется, является одним из главных явлений, познание которого позволит военной психологии доказать свою состоятельность.

\section{Литература}

1. Белоусов А. В., Караяни А.Г. Отечественная психология в годы Великой Отечественной войны // Инновации в образовании. - 2005. - № 3. - С. 128-147.

2. Боринг Э. Психология для Вооруженных Сил. - Вашингтон: Изд-во Гарвардского университета, 1943.

3. Габриэль Р. Героев больше нет. - Нью-Йорк, 1987.

4. Казаринов О. И. Неизвестные лики войны. Между жизнью и смертью. M., 2005.

5. Караяни А. Г.Слухи как средство информационно-психологического противодействия // Психологический журнал. - 2003. - Т. 24. - № 6. - С. 47-54.

6. Караяни А. Г, Сыромятников И. В. Введение в профессию военного психолога. - М.: Академия, 2007.

7. Клаузевиц К. фон. О войне. В 2 т.: Т. 1. - М.: АСТ, 2002.

8. Корф Н. А. О воспитании воли военачальников // Общество ревнителей военных знаний. - 1906. - Кн. 1. - С. 163, 246.

9. Макнаб К. Психологическая подготовка подразделений специального назначения. - М., 2002.

10. Маршалл С. Л. А. Американцы в бою / Офицер вооруженных сил. Пер. с англ. - Вашингтон, 1991.

11. Мокор П. Х. Военная психология и реальность боя // Современная буржуазная военная психология. - 1964. - С. 47-63.

12. Момыш-улы Б. Психология войны. - Алматы: Казахстан, 1996.

13. Полянский В. Н. Моральный элемент в области фортификации. - СПб., 1910. - C. 53-54. 
14. Симонов П. В. Мотивированный мозг. - М.: Наука, 1987.

15. Франкл В. Человек в поисках смысла. Пер. с англ. - Вашингтон, 1985.

16. Шумков Г. Е. Чувство тревоги как доминирующая иллюзия в период ожидания боя // Военный сборник. - 1913.

17. Эмоциональный стресс. Физиологические и психологические реакции. Медицинские, индустриальные и военные последствия стресса. Пер. с англ. - М.: Медицина, 1970.

18. Horn B. The worm revisited: An examination of fear and courage in combat // URL: http://www.journal.dnd.ca/vo5/no2/doc/leadership-direction-eng.pdf 